\title{
QBD BASED ANALYTICAL METHOD DEVELOPMENT AND VALIDATION FOR THE SEPARATION AND QUANTIFICATION OF AGOMELATINE AND ITS IMPURITIES IN SOLID ORAL DOSAGE FORMS USING HPLC
}

\author{
Somana Siva Prasad, Bikshal Babu Kasimala and Venkateswara Rao Anna ${ }^{凶}$ \\ Department of Chemistry, Koneru Lakshmaiah Education Foundation, Vaddeswaram, Guntur \\ District, Andhra Pradesh-522502 \\ ${ }^{\square}$ Corresponding Author: avrchemistry@gmail.com
}

\begin{abstract}
A simple and precise reversed-phase high-performance liquid chromatographic (HPLC) method was developed for the separation of Agomelatine and its impurities in the tablet dosage form. The method was developed by utilizing the quality by design (QbD) statistical approach. The method optimized as $\mathrm{pH} 2.6$ buffer containing potassium dihydrogen orthophosphate $\left(\mathrm{KH}_{2} \mathrm{PO}_{4}\right)$ and 1-octane sulphonic acid sodium salt anhydrous and Acetonitrile in the ratio of 80:20 (v/v) as mobile phase A and Milli-Q water and acetonitrile in the ratio of 20:80 (v/v) as mobile phase $\mathrm{B}$ in gradient elution and separation was achieved on Symmetry Shield RP-18, 150 X $4.6 \mathrm{~mm}, 3.5 \mu \mathrm{m}$ column as stationary phase and UV detection at 230nm. The quantitation limits of Agomelatine AGL-5D impurity, Desmethyl impurity, $5^{\text {th }}$ Isomer impurity, AGL-4D impurity, and hydroxy impurities are found to be $0.05,0.04,0.06,0.05$, and 0.04 respectively. Recovery studies from (limit of quantification level to $150 \%$ level) $0.05 \mu \mathrm{g} / \mathrm{mL}$ to $150 \mu \mathrm{g} / \mathrm{mL}$ are performed for all impurities and results are in the range of 97.5-101.2\%. The method can separate impurities studied and the forced degradation compounds formed and hence the method can effectively use for the analysis of impurities of Agomelatine and stress degradation compounds.

Keywords: Agomelatin, HPLC Analysis, Quality by Design Approach, Method Validation.
\end{abstract}

RASĀYAN J. Chem., Vol. 14, No.4, 2021

\section{INTRODUCTION}

Agomelatine belongs to antidepressant class medication prescribed for the treatment of major depressive disorder ${ }^{1}$ and is proved to be effective than other antidepressants with fewer discontinuations due to side effects. ${ }^{2}$ Agomelatine is an agonist of melatonin which is naturally secreted by pineal gland that regulates circadian rhythms/sleep patterns. ${ }^{3}$ The antidepressant activity of Agomelatine is due to its antagonist activity against both serotonin $(5-\mathrm{HT})(2 \mathrm{C})$ receptors and melatonin receptors (MT1 and MT2). ${ }^{4}$ In healthy volunteers, Agomelatine does not alter memory and daytime vigilance but in patients with depression, it increases the slow-wave sleep without modification of Rapid Eye Movement. ${ }^{5}$ Nausea, headaches, fatigue, liver problems weight gain and anxiety are the possible side effects associated with the use of Agomelatine. Agomelatine is not recommended for patients with dementia and over the age of $75 .^{6,7}$

The literature survey for the analysis of Agomelatine using different analytical techniques confirms that one HPLC assay method ${ }^{8}$, HPLC stability-indicating methods ${ }^{9,10}$ and UV spectrophotometer methods ${ }^{11,12}$ reported for the analysis of Agomelatine in pharmaceutical formulations. One UPLC method ${ }^{13}$ and two LCMS methods ${ }^{14-15}$ were reported for the estimation of Agomelatine in different biological samples. One HPLC was reported for the estimation of Agomelatine and its related impurities in formulations. ${ }^{16}$ The present work aimed to develop a simple and precise method for the estimation of Agomelatine and its related substances (5D Impurity, Desmethyl Impurity, 5th isomer Impurity, 4D Impurity and Hydroxy Impurity) in pharmaceutical formulations. Agomelatine molecular structure was given in Fig.-1.

\section{Equipment's and Chemical Reagents}

HPLC system (Waters, USA) with a quaternary solvent delivery system, UV-Visible and Photodiode Array (PDA) detector and Empower-3 software. The standard drug Agomelatine (98.75\% purity) and its process impurities 5D Impurity, Desmethyl Impurity, $5^{\text {th }}$ isomer Impurity, 4D Impurity and Hydroxy Rasayan J. Chem., 14(4), 2183-2190(2021)

http://doi.org/10.31788/RJC.2021.1446426 
Impurity were obtained from Eisai Pharmaceuticals India, Pvt. Ltd, Paravada, Visakhapatnam, Andhra Pradesh. Acetonitrile (HPLC grade), 1-octane sulphonic acid sodium salt (LR grade), potassium dihydrogen orthophosphate (LR grade) was purchased from Merck KGaA (Germany).

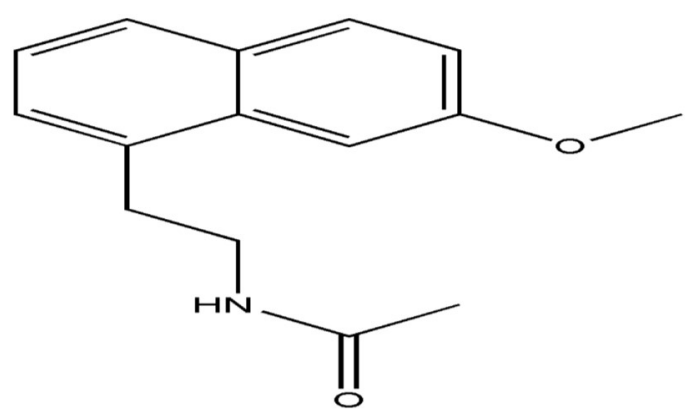

Fig.-1: Molecular Structure of Agomelatine

\section{EXPERIMENTAL}

\section{Preparation of Agomelatine Standard Solution}

Agomelatine standard solution was prepared by dissolving $50 \mathrm{mg}$ in $100 \mathrm{~mL}$ of solvent. $4 \mathrm{~mL}$ of the solution was made up to $200 \mathrm{~mL}$ in a $200 \mathrm{~mL}$ volumetric flask. Then $42 \mathrm{~mL}$ of the dilute solution was pipetted accurately and was made up to $100 \mathrm{~mL}$ in a $100 \mathrm{~mL}$ volumetric flask. The solution was used as Agomelatine standard solution during the experiment.

\section{Impurity Stock Solution}

An accurately weighed $1.0 \mathrm{mg}$ of each AGL-5D Impurity, Desmethyl Impurity, AGL 5th isomer Impurity, AGL-4D Impurity and Hydroxy Impurity were transferred into a $10 \mathrm{~mL}$ volumetric flask, add 5 $\mathrm{mL}$ of diluent. Then it was dissolved completely using sonication and filtered before the experiment.

\section{System Suitability Solution}

The system suitability solution containing Agomelatine standard and its known impurities with known concentrations was prepared by mixing $10 \mathrm{~mL}$ of Agomelatine standard solution and impurity stock solution.

\section{Test Solution Preparation}

Twenty tablets of Agomelatine were powdered to fine and uniform and weigh an amount equivalent to $100 \mathrm{mg}$ of Agomelatine and was dissolved in $70 \mathrm{~mL}$ of diluent in a $100 \mathrm{~mL}$ volumetric flask and sonicate to dissolve the drug in solvent and filtered. Then the final volume was made to $100 \mathrm{~mL}$ and was used as a sample stock solution for the analysis of Agomelatine.

\section{Forced Degradation Study}

Forced degradation study was carried to ascertain the effective separation of known impurities and unknown degradation products formed during the stress degradation study of Agomelatine in the developed method. Agomelatine exposed to different stress degradation conditions like acidic with $0.1 \mathrm{~N}$ hydrochloric acid $(\mathrm{HCl})$, base degradation with $0.1 \mathrm{~N}$ sodium hydroxide $(\mathrm{NaOH})$, oxidative degradation with $30 \%$ hydrogen peroxide $\left(\mathrm{H}_{2} \mathrm{O}_{2}\right)$, thermal degradation with exposing Agomelatine at $80^{\circ} \mathrm{C}$ in hot air oven, aqueous degradation with $3 \mathrm{~mL}$ of water in 3 days, light degradation with 1.2 million lux-hrs, 90\% humidity exposer and 200 watt/H UV light degrdation. ${ }^{17-22}$

\section{RESULTS AND DISCUSSION}

To acquire optimum resolution between Agomelatine and its impurities studied, different organic modifiers like acetonitrile and methanol were studied. Different buffer compositions like sodium perchlorate, formic acid buffers, ammonium salts, 1-octane sulphonic acid sodium salt anhydrous and phosphate buffers and columns with different sizes and companies were studied.

The standard Agomelatine and its all impurities studied have different elution nations and show different retention behaviour. Hence it is challenging for the development of a method for the separation of 
compounds with different retention nature without interfering with Placebo components and degradation compounds.

In the HPLC analysis Design of Experiments (DOE) is the best tool used for the determination of optimized conditions using statistical methodology. The optimized conditions observed in DOE statistical approach was given in table 1 . In the DOE approach, mobile phase flow rate, $\mathrm{pH}$ of the mobile phase, $\%$ composition of organic modifier i.e acetonitrile was optimized by considering the resolution between the Hydroxy impurity and Agomelatine which are the close eluting compounds in the study.

In the optimization study by DOE statistical methodology, the factors that are affecting the resolution, Pareto chart with three-dimensional plots generation and modeling of results obtained was carried using Minitab software. The composition of acetonitrile and the $\mathrm{pH}$ of the buffer play a key role in the separation of Agomelatine and its impurities studied. The results observed on DOE statistical methodology were very close to the results observed in experimental data confirms that the design space was established in the method developed for the separation of Agomelatine and impurities. Visual inspection and modelled data were used to perform interactive effects and various overlay graphs plotted against two parameters ta a time. The results observed in the DOE study were given in Fig. -2 to 5.

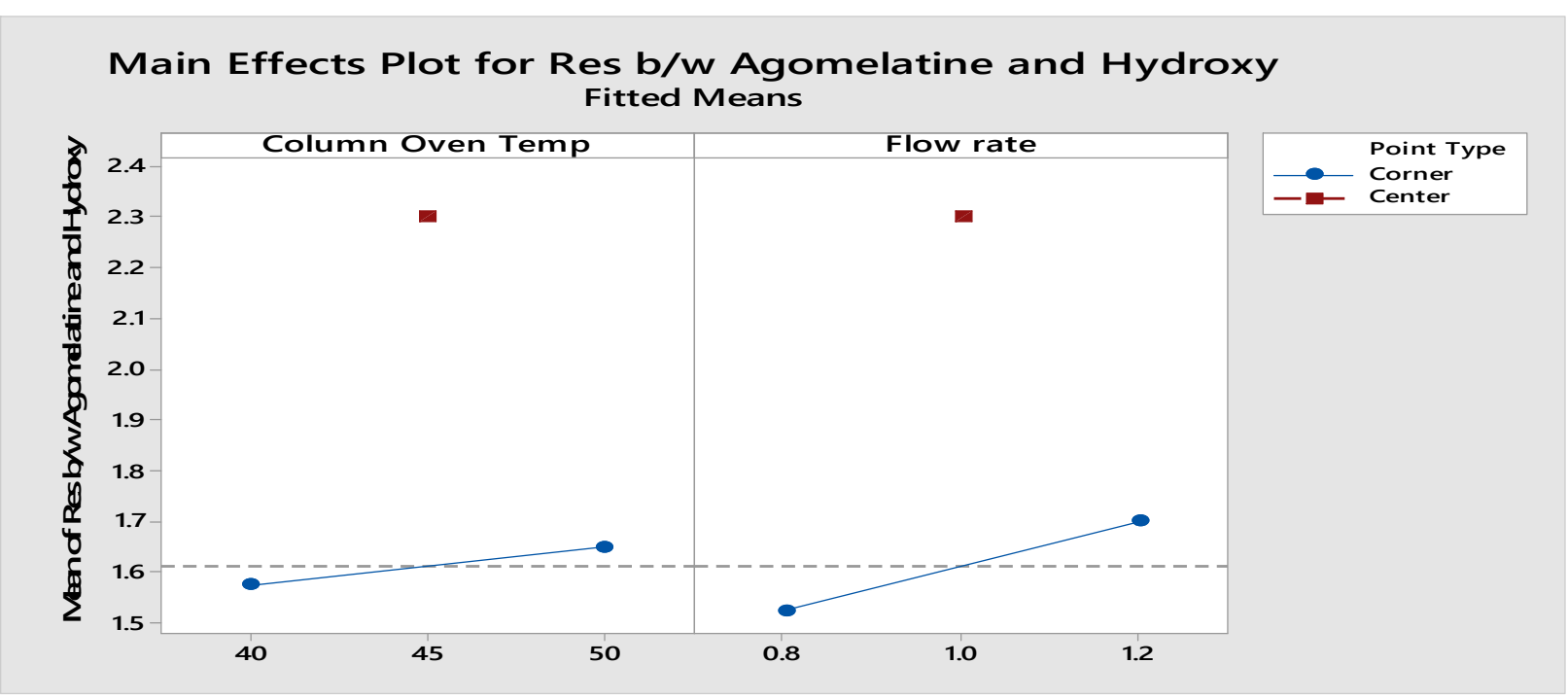

Fig.-2: Main Effect Chart Showing the Resolution between Agomelatine and Hydroxy Impurity

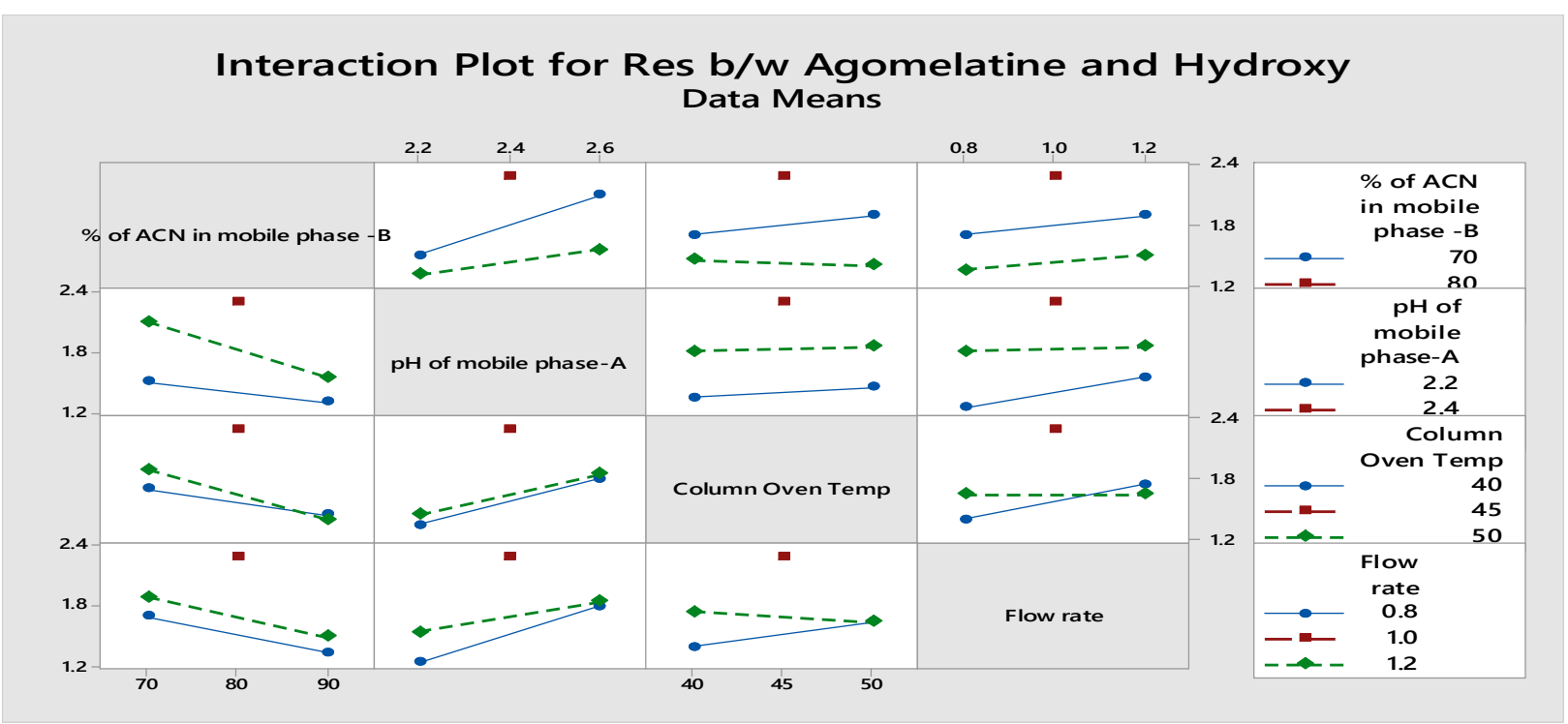

Fig.-3: The Interaction Plot Showing Resolution between Standard and Hydroxy Impurity. 
RASĀYAN J. Chem.

Vol. 14 | No. 3 |2183-2190| October - December | 2021

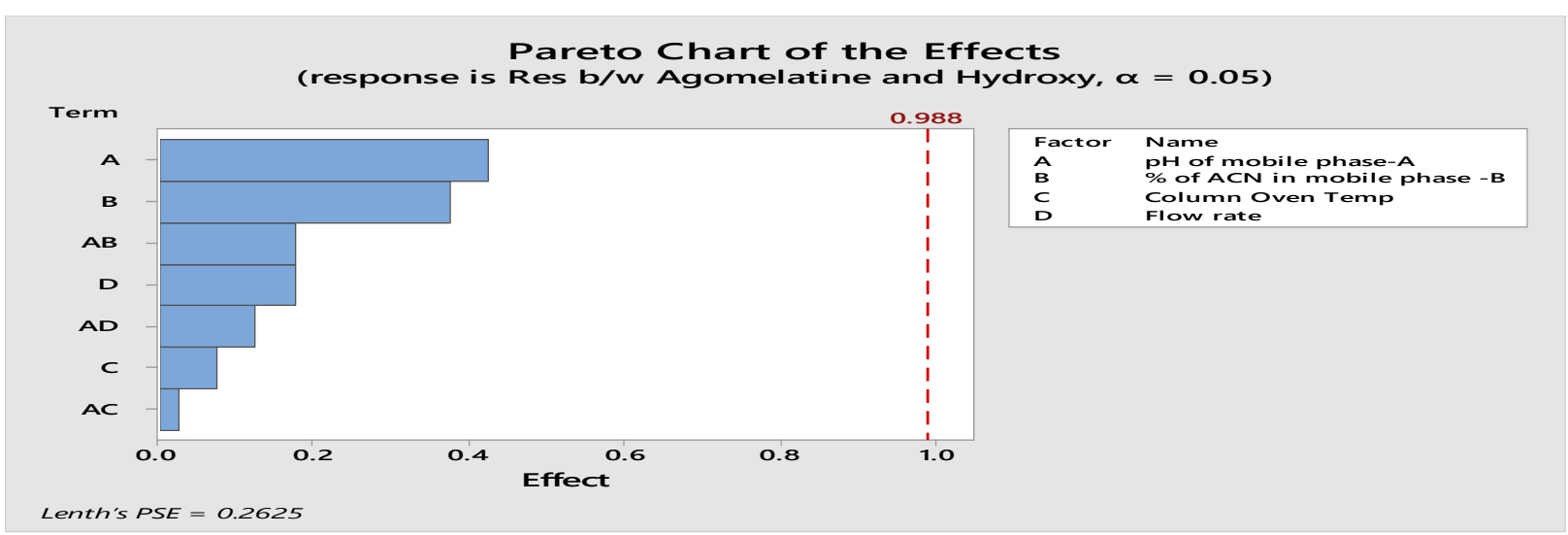

Fig.-4: The Pareto Chart for Standardized Effects on the Resolution between Agomelatine and Hydroxy Impurity.

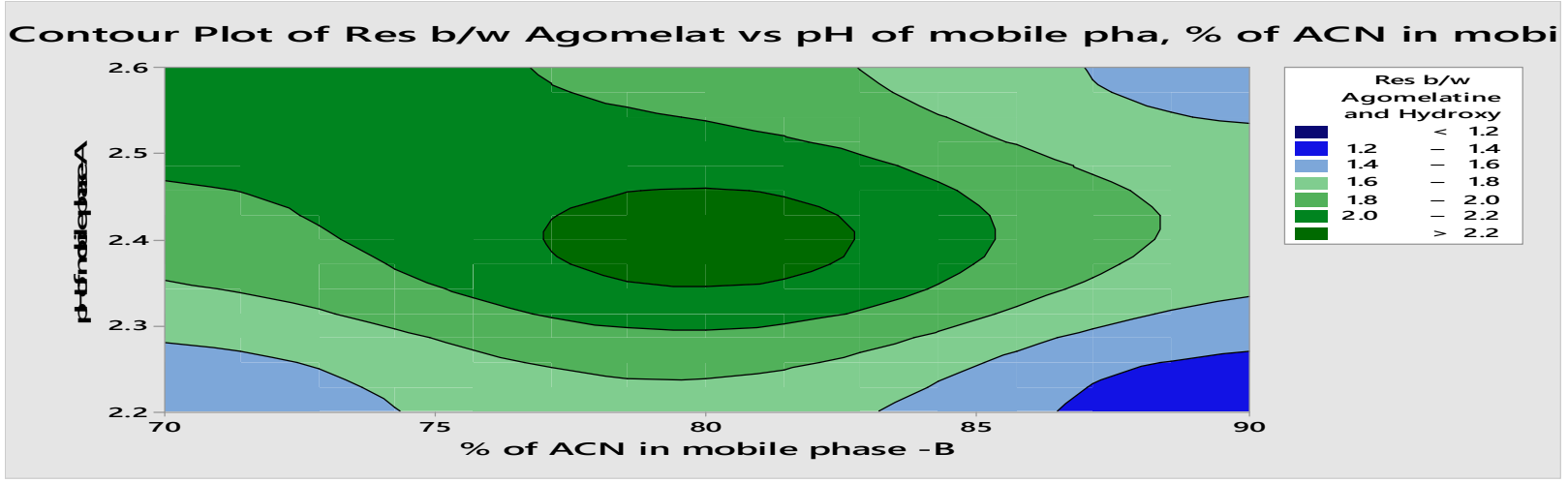

Fig.-5: The Contour Plot Showing Resolution between Agomelatine and Hydroxy Impurity

Table-1: Conditions of HPLC Method

\begin{tabular}{|c|c|c|c|c|}
\hline Stationary Phase & \multicolumn{4}{|c|}{ Symmetry Shield RP-18, 150 X $4.6 \mathrm{~mm}, 3.5 \mu \mathrm{m}}$. \\
\hline Stationary Phase Temperature & \multicolumn{4}{|c|}{$45^{\circ} \mathrm{C}$} \\
\hline Sample Cooler Temperature & \multicolumn{4}{|c|}{$5^{\circ} \mathrm{C}$} \\
\hline Wavelength & \multicolumn{4}{|c|}{$230 \mathrm{~nm}$} \\
\hline Sample Volume & \multicolumn{4}{|c|}{$10 \mu \mathrm{L}$} \\
\hline Run Time & \multicolumn{4}{|c|}{ 70minutes } \\
\hline Mobile Phase Composition & \multicolumn{4}{|c|}{$\begin{array}{l}\text { Mobile phase A: } \mathrm{pH} 2.6 \text { buffer containing potassium dihydrogen } \\
\text { orthophosphate }\left(\mathrm{KH}_{2} \mathrm{PO}_{4}\right) \text { and 1-octane sulphonic acid sodium salt } \\
\text { anhydrous and Acetonitrile in the ratio of } 80: 20(\mathrm{v} / \mathrm{v}) \\
\text { Mobile phase B:Milli-Q water and acetonitrile in the ratio of } 20: 80(\mathrm{v} / \mathrm{v})\end{array}$} \\
\hline Gradient & $\begin{array}{c}\text { Time } \\
\text { (minutes) } \\
0 \\
5 \\
30 \\
50 \\
60 \\
60.1\end{array}$ & $\begin{array}{c}\% \text { of Mobile } \\
\text { Phase A } \\
85 \\
85 \\
45 \\
0 \\
0 \\
85\end{array}$ & $\begin{array}{c}\% \text { of Mobile } \\
\text { Phase B } \\
15 \\
15 \\
55 \\
100 \\
100 \\
15\end{array}$ & $\begin{array}{l}\text { Flow Rate } \\
1.0 \mathrm{ml} / \mathrm{min} \\
1.0 \mathrm{ml} / \mathrm{min} \\
1.0 \mathrm{ml} / \mathrm{min} \\
1.0 \mathrm{ml} / \mathrm{min} \\
1.0 \mathrm{ml} / \mathrm{min} \\
1.0 \mathrm{ml} / \mathrm{min}\end{array}$ \\
\hline
\end{tabular}

The shape of the individual peaks, recovery of all compounds study and greater threshold than the limit of quantification (LOQ) was considered for optimizing the test concentrations, diluent and volume of sample. In the optimized conditions, Fig.-6 represents the chromatogram for the blank, Fig. -7 is the chromatogram for the standard, Fig.-8 is the chromatogram for the placebo preparation, Fig.- 9 represents the chromatogram for the sample preparation and Fig.-10 represents the chromatogram for the spiked sample preparation. 
RASĀYAN J. Chem.

Vol. 14 | No. 3 |2183-2190| October - December | 2021

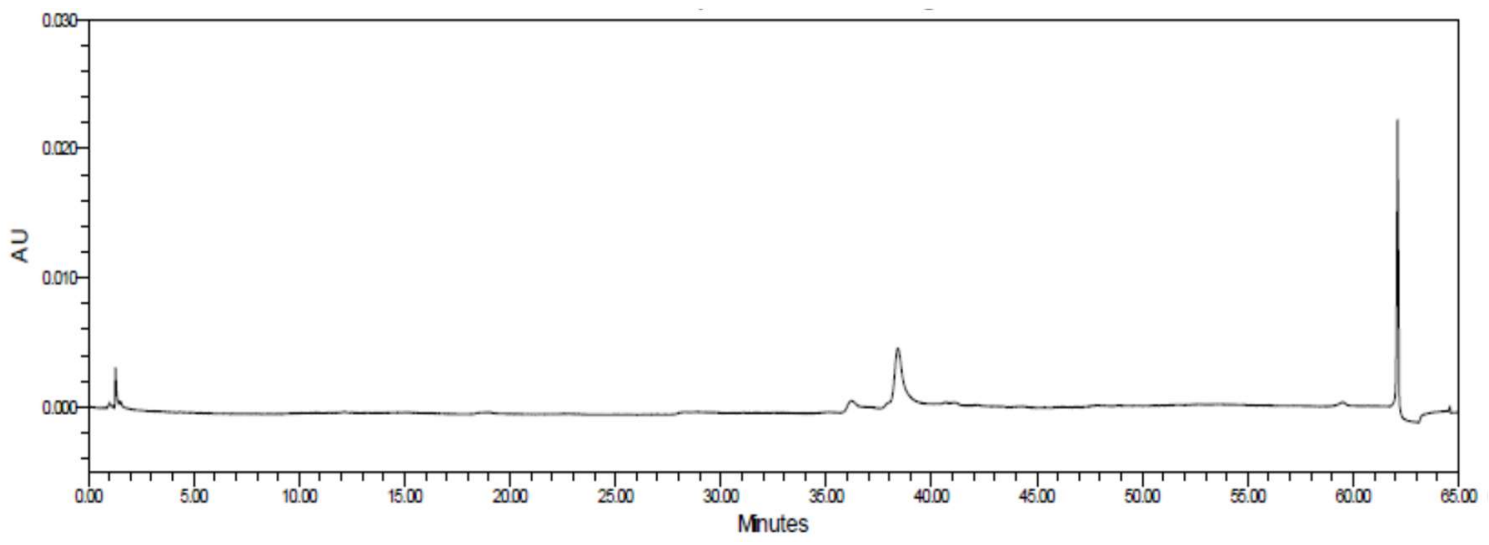

Fig.-6: The Chromatogram for Blank Preparation

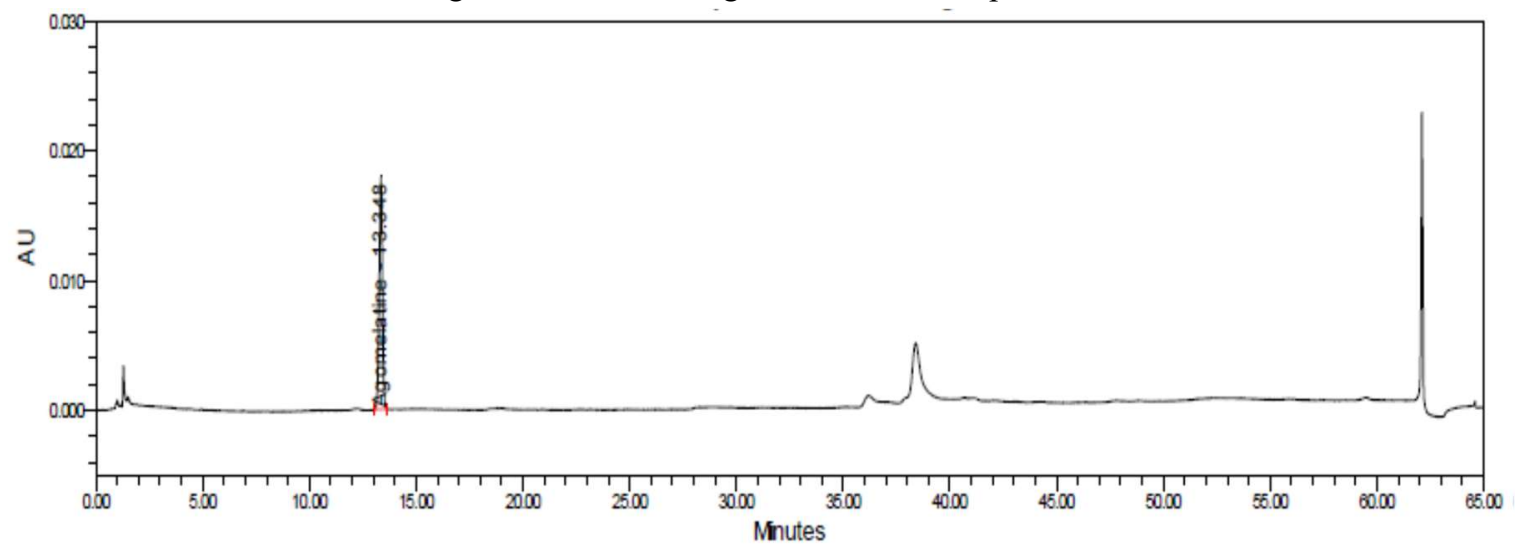

Fig.-7: The Chromatogram for Standard Preparation

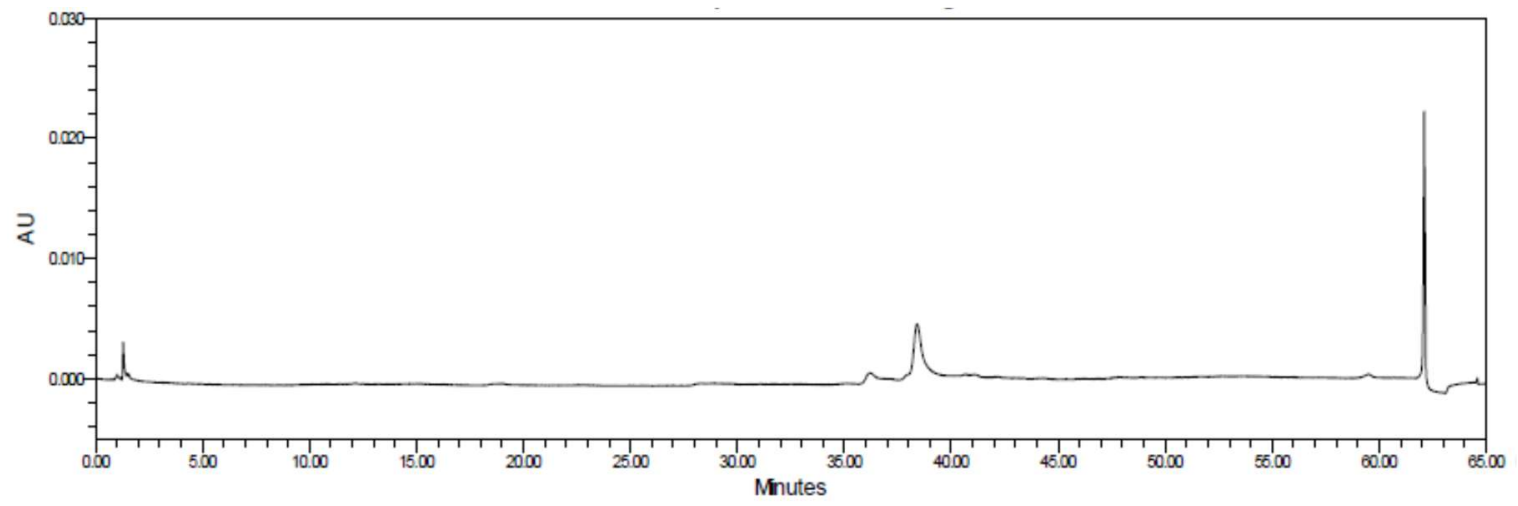

Fig.-8: The Chromatogram for Placebo Preparation

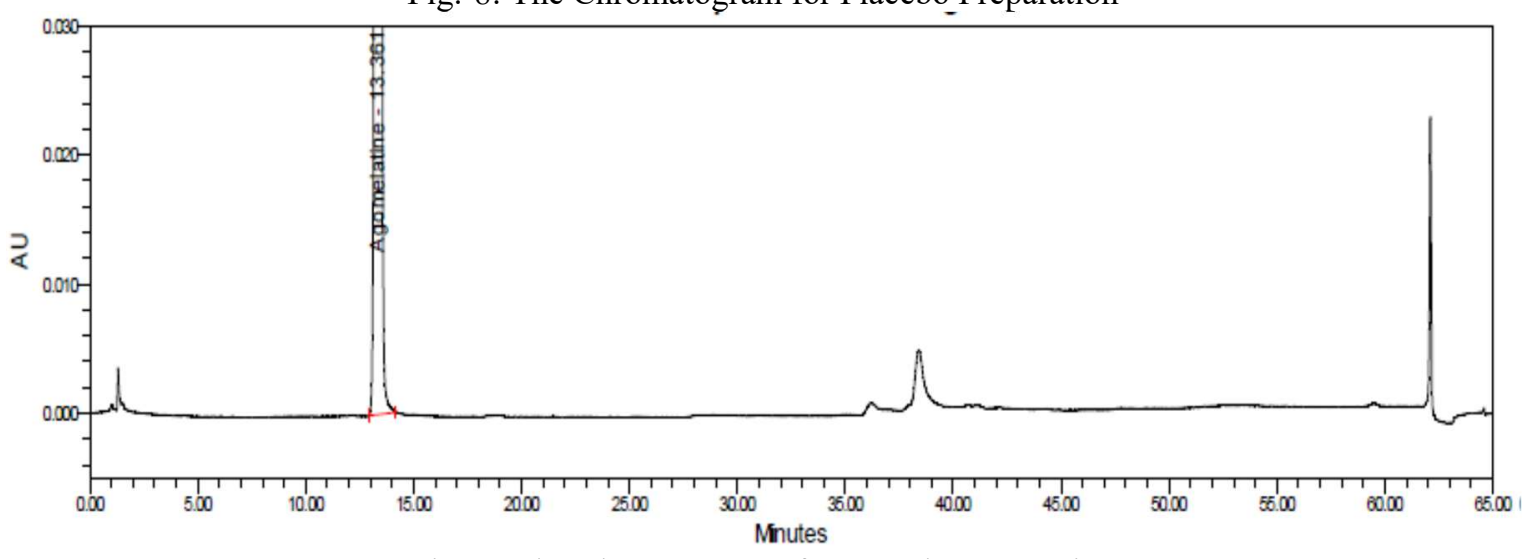

Fig.-9: The Chromatogram for Sample Preparation 


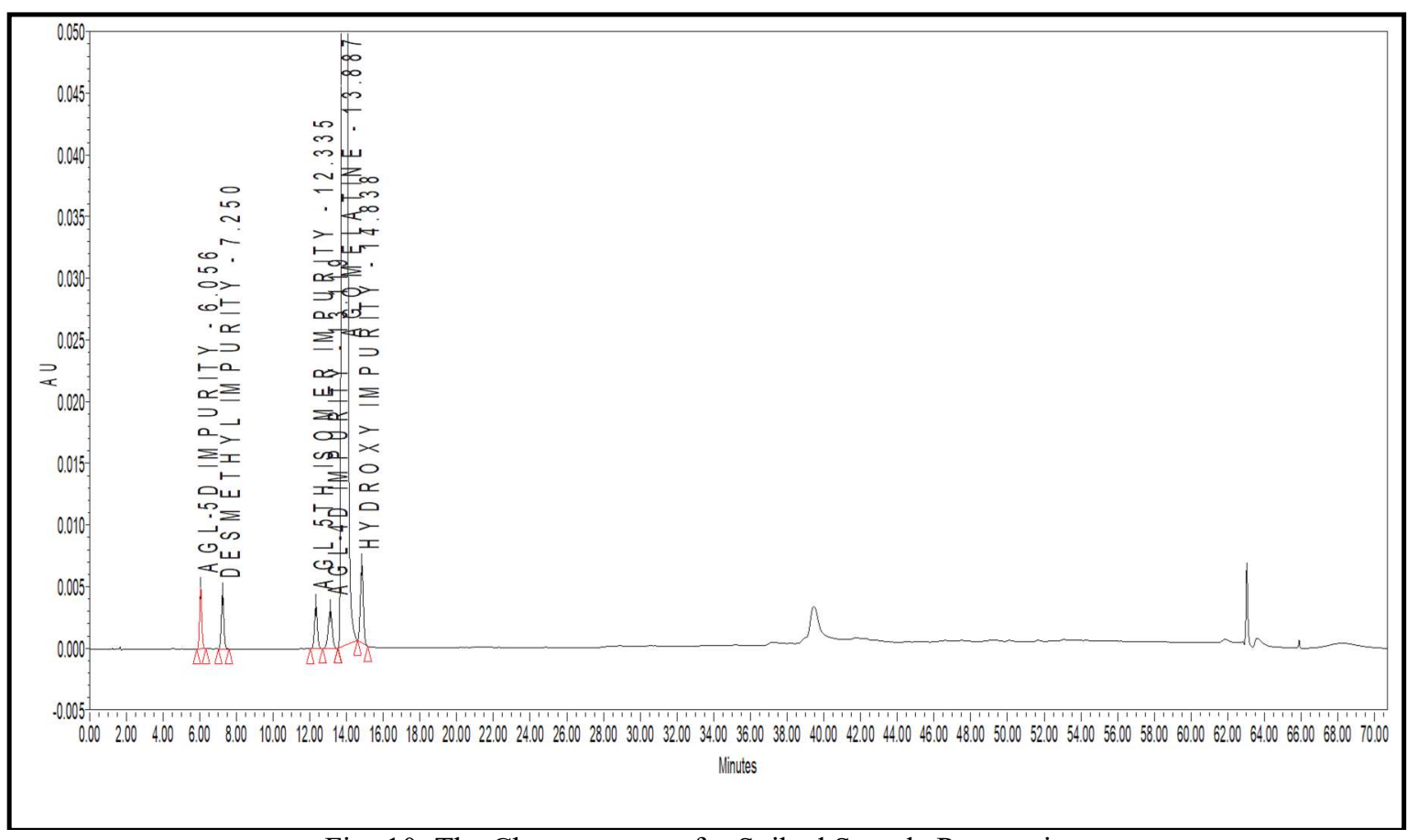

\section{Method Validation}

Fig.-10: The Chromatogram for Spiked Sample Preparation

The system suitable solution with $0.2 \%$ standard level with all analytes was prepared and analyzed in the developed method. The \% RSD (relative standard deviation) was calculated tailing factors of Agomelatine peak and peak areas observed for Agomelatine and its impurities studied. The \% RSD for Agomelatine peak area response and tail factor was found to be 1.24 and 1.09 respectively which is within the acceptable limit. The findings are depicted in Table-2.

Table-2: System Suitability Parameters

\begin{tabular}{|c|c|c|}
\hline System Suitability Parameters & Observation & Acceptance Criteria \\
\hline Tailing factor for Agomelatine & 1.09 & $<1.5$ \\
\hline$\%$ RSD for areas of Agomelatine & 1.24 & $<10$ \\
\hline Resolution between Agomelatine and Hydroxy impurity & 2.8 & $>1.5$ \\
\hline
\end{tabular}

The solution stability of the Agomelatine and AGL-5D impurity, Desmethyl impurity, $5^{\text {th }}$ Isomer impurity, 4D impurity, and hydroxy impurity in the spiked sample was determined by incubating the solution on the bench-top for $24 \mathrm{~h}$ at room temperature. The results were compared with a fresh standard solution and the \% stability was found to be within the acceptable limit for Agomelatine and impurities. The Agomelatine standard with different stress conditions was analyzed in the HPLC system with a PDA detector stabilized with the developed method to evaluate the purity Agomelatine peak and identify the unknown peaks in the degradation study. The results observed in the stress study confirm that the purity threshold was found to be higher than the purity angle for unknown compounds formed in the stress study and Agomelatine standard (Table-3) and the method can separate the degradation products. This confirms the selectivity of the method for the separation of Agomelatine impurities and stress degradation compounds.

Table-3: Peak Purity and Degradation Results for Agomelatine in Stress Study

\begin{tabular}{c|c|c|c|c|c|c}
\hline S. No. & Stress Condition & $\begin{array}{c}\% \text { Net } \\
\text { Degradation }\end{array}$ & $\begin{array}{c}\text { Purity } \\
\text { Angle }\end{array}$ & $\begin{array}{c}\text { Purity } \\
\text { Threshold }\end{array}$ & $\begin{array}{c}\text { Purity } \\
\text { Flag }\end{array}$ & $\begin{array}{c}(\%) \text { Mass } \\
\text { Balance }\end{array}$ \\
\hline 1 & Un stressed sample & NA & 0.103 & 0.414 & NO & NA \\
\hline 2 & Acid stress & 6.21 & 0.085 & 0.421 & NO & 97 \\
\hline 3 & Base stress & 4.84 & 0.184 & 0.508 & NO & 96 \\
\hline 4 & Aqueous stress & 1.93 & 0.194 & 0.454 & NO & 97 \\
\hline
\end{tabular}


RASĀYAN J. Chem.

Vol. 14 | No. 3 |2183-2190| October - December | 2021

\begin{tabular}{c|c|c|c|c|c|c}
\hline 5 & Peroxide stress & 10.50 & 0.241 & 0.556 & NO & 95 \\
\hline 6 & Dry heat stress & 3.66 & 0.131 & 0.373 & NO & 101 \\
\hline 7 & Humidity stress & 1.38 & 0.141 & 0.404 & NO & 100 \\
\hline 8 & UV light stress & 2.07 & 0.134 & 0.369 & NO & 96 \\
\hline
\end{tabular}

The linearity range was evaluated above the series of the limit of quantification (LOQ) level to $150 \%$ level for the main analyte and all impurities (AgomelatineAGL-5D impurity, Desmethyl impurity, $5^{\text {th }}$ Isomer impurity, AGL-4D impurity, and hydroxy impurity). The prepared calibration dilutions were analyzed into the HPLC system, and the results show that the calibration dilution was in good correlation and the method was found to be linear within the concentration studied.

The limit of detection (LOD) and LOQ were prepared by spiking the Agomelatine standard dilutions to the standard Agomelatine solution. The LOD and LOQ were determined using the formula $\mathrm{LOD}=3.3 \times \sigma / \mathrm{S}$ and $\mathrm{LOQ}=10 \times \sigma / \mathrm{Sin}$ which $\mathrm{s}$ is the slope of the linearity curve and $\sigma$ is the standard deviation of peak area responses. The results show (Table-4) the very sensitive limits for Agomelatine standard and impurities studied which confirms the sensitivity of the method.

The $\%$ recovery in spiked recovery performing at 50\%, 100\% and $150 \%$ spiked levels were found to be within the acceptable limits and the \% recovery and the \% RSD in intraday and interday precision study results were also observed to be within the acceptable limit (Table 4) proves that the method is precise and accurate.

The method was applied for the separation and quantification of Agomelatine and its impurities in pharmaceutical formulations and it was observed that the method can accurately separate and identify the drug Agomelatine and its impurities in pharmaceutical formulations. A very high $\%$ assay of more than 98 was observed for standard Agomelatine and an acceptable \% of less than 0.2 was observed for all the impurities in the study. The developed method was compared with the available method in the literature ${ }^{16}$ and confirms that the method reported in the present study was found to be more accurate, precise and sensitive confirms that the method can successfully be utilized for the separation and analysis of Agomelatine and it's in bulk drug as well as in formulations.

Table-4: Results Observed in Method Validation Study for Agomelatine

\begin{tabular}{c|c|c|c|c|c}
\hline Parameters & $\begin{array}{c}\text { AGL-5D } \\
\text { Impurity }\end{array}$ & $\begin{array}{c}\text { Desmethyl } \\
\text { Impurity }\end{array}$ & $\begin{array}{c}5^{\text {th }} \text { Isomer } \\
\text { Impurity }\end{array}$ & $\begin{array}{c}\text { AGL-4D } \\
\text { Impurity }\end{array}$ & $\begin{array}{c}\text { Hydroxy } \\
\text { Impurity }\end{array}$ \\
\hline LOQ (\%) & 0.05 & 0.04 & 0.06 & 0.05 & 0.04 \\
\hline LOD (\%) & 0.03 & 0.02 & 0.03 & 0.03 & 0.02 \\
\hline Precision & $100.4-101.8$ & $102.6-100.5$ & $99.0-98.9$ & $102.7-101.3$ & $99.6-101.8$ \\
\hline LOQ & $101.7-100.9$ & $98.7-96.1$ & $99.6-99.7$ & $100.7-99.8$ & $98.9-101.9$ \\
\hline $50 \%$ & 98.5 & 96.7 & 100.5 & 100.5 & 99.7 \\
\hline $100 \%$ & 99.5 & 97.5 & 101.2 & 99.8 & 98.9 \\
\hline $150 \%$ & 100.1 & 98.7 & 100.9 & 99.1 & 99.1 \\
\hline
\end{tabular}

\section{CONCLUSION}

A simple and accurate RP-HPLC method was developed based on the quality by design approach for the analysis of Agomelatine and its related compounds and degradation products. The method was validated in terms of accuracy/recovery, range, specificity and other parameters and found to be acceptable. DOE statistical methodology was applied for the optimization of critical method parameters. The method can effectively separate the unknown impurities in the degradation and can be used for the analysis of Agomelatine impurities and unknown degradation compounds.

\section{ACKNOWLEDGEMENT}

The authors thank the management of Dr. Reddy's Laboratories Ltd. for their valuable support to carry out and publish the work.

\section{REFERENCES}

1. D. Taylor, A. Sparshatt, S. Varma, O Olofinjana. British Medical Journal, 348, 1888(2014), https://doi.org/10.1136/bmj.g1888

2. Andrea Cipriani, Toshi A Furukawa, Georgia Salanti, Anna Chaimani, Lauren Z. Atkinson, Yusuke Ogawa, Stefan Leucht, Henricus G Ruhe, Erick H Turner, Julian P T Higgins, Matthias Egger, 2189 
RASĀYAN J. Chem.

Vol. 14 | No. 3 |2183-2190| October - December | 2021

Nozomi Takeshima, Yu Hayasaka,Hissei Imai, Kiyomi Shinohara, Aran Tajika, John P A Ioannidis, John R Geddes, The Lancet, 391(10128), 10128(2018), https://doi.org/10.1016/S01406736(17)32802-7

3. G. Derek, G. Waller. and P. Anthony, Depression, Attention Deficit Hyperactivity Disorder and Narcolepsy, Medical Pharmacology and Therapeutics (Fifth Edition), pp 297-310 (2018),

4. B. Guardiola-Lemaitre,C. De Bodinat,P. Delagrange,M. J. Millan,C. Munoz, E. Mocaër, British Journal of Pharmacology, 171(15), 3604(2014), https://doi.org/10.1111/bph.12720

5. Quera Salva, The International Journal of Neuropsychopharmacology, 10(5), 691(2007), https://doi.org/10.1017/S1461145707007754

6. T.R. Norman, J.S. Olver, Expert Opinion on Pharmacotherapy, 20(6), 647(2019), https://doi.org/10.1080/14656566.2019.1574747

7. S.A. Montgomery, S. Kasper, International Clinical Psychopharmacology, 22(5), 283(2007), https://doi.org/10.1097/YIC.0b013e3280c56b13

8. Sai Govikari, Bairi Agaiah Goud and Ajmera Rama Rao, World Journal of Pharmaceutical and Life Sciences, 2(4), 482(2016).

9. Maha M. Abdelrahman, Ibrahim A. Naguib, Mohamed R. El Ghobashy, Nesma A. Ali, Journal of Chromatographic Science, 56(4), 317(2018), https://doi.org/10.1093/chromsci/bmx114

10. R.N. El-Shaheny, Luminescence, 29(7), 920(2014), https://doi.org/10.1002/bio.2642

11. Rupareliya, Reema and Joshi Hitendra, International Letters of Chemistry, Physics and Astronomy, 56 (2015), https://doi.org/10.18052/www.scipress.com/ILCPA.56.113

12. Fábio de Souza Barbosa, Vanise Coty Rodrigues, Nadia M. Volpato, Elfrides E. S. Schapoval, Martin Steppe, Cássia V. Garcia, Andreas S. L. Mendez, Drug Analitical Research, 1(2), 24(2017).

13. Georgios N. Rallis , Petros Petrikis and Vassiliki A. Boumba, Annals of Chromatography and Separation Techniques, 2(2), 1020(2016), https://doi.org/10.36876/acst.1020

14. Xiaolin Wang, Dan Zhang, Man Liu, Hongna Zhao, Aihua Du, Lingjie Meng, Huichen Liu, Biomedical Chromatography, 28(2), 218(2014), https://doi.org/10.1002/bmc.3008

15. Satish R. Patil, Ketan K. Nerurkar, Ashok M. Kalamkar, Vishwas Pukale, Kiran V. Mangaonkar, Satish G. Pingale, Journal of Mass Spectrometry, 47(1), 23 (2012), https://doi.org/10.1002/jms.2020

16. Luo Junqiu, Lu Chunxiao and Yan Chao, Journal of Pharmaceuticals, 47, 10(2016), https://doi.org/16522/j.cnki.cjph.2016.10.020

17. S.S. Prasad, G.V.K. Mohan, A.N. Babu, Rasayan Journal of Chemistry, 12(3), 1434(2019), https://doi.org/10.31788/RJC.2019.1235281

18. K. Sri Girija, Bikshal Babu Kasimala, Venkateswara Rao Anna, International Journal of Applied Pharmaceutics, 13(2), 165(2021), https://doi.org/10.22159/ijap.2021v13i2.39895

19. P. Geetha Swarupa, KRS Prasad, K Suresh Babu, JV Shanmukha Kumar, Rasayan Journal of Chemistry, 12(4), 2338(2019), https://doi.org/10.31788/RJC.2019.1245438

20. B.K. Bikshal, RM Useni, R.A. Venkateswara, RL Maheshwara, Thai Journal of Pharmaceutical Sciences, 42(1), 27(2018).

21. S.K. Palacharla, G.V. Krishna Mohan, Rasayan Journal of Chemistry, 11(4), 1696(2018) https://doi.org/10.31788/RJC.2018.1144093

22. U.R. Mallu, V.R. Anna, B.B. Kasimala, Turkish Journal of Pharmaceutical Sciences, 16(4), 457(2019) https://doi.org/10.4274/tjps.galenos.2018.34635

[RJC-6426/2021] 